\title{
Interdiscursivity in Public Relations Communication: Appropriation of Genre and Genre Resources
}

\author{
"Language is power, and the power of language is the 'power of genre'. Power of genre is not only to \\ construct, use, interpret and exploitgenres, but also to innovate novel generic forms." (Bhatia 2004: \\ 189)
}

\begin{abstract}
Undoubtedly, in recent years, the world as a whole, as well as the present world of work, has seen rapid changes which have served to bring about fundamental changes to work practices. Employees and trainers are thus facing greater challenges to achieve the required competency needed in this changing workplace environment.

Bhatia (2013) observes that while the analyses of legal discourse have focused largely on 'discursive practices', very little effort has been given to studying 'critical performance' in professional legal practices, which is distinct from discursive practices. For this reason, this paper aims to show why discursive output has proved insufficient in the dynamic and complex discourse world of the present day workplace, as well as how the application of Critical Genre Analysis (CGA) greatly assists our understanding of it. By using critical genre theory, this paper looks more closely at interdiscursivity in public relations (PR) involving professional communication and how this in turn results in greater understanding of the changing workplace environment of the PR profession and helps individual PR practitioners cope with the challenges that they face.

To achieve these aims, this study includes (i) in-depth interviews with public relations practitioners to gain their perceptions of their daily activities and the language and communication skills required by public relations practitioners to improve their effective professional communication, and (ii) critical genre analysis of the production of PR/ communication plans, in particular, the Executive Summary and the Situation Analysis Section of the plans, to show the interaction between discursive and professional practices in the "socio-pragmatic space" of public relations contexts and how interdiscursivity is built into PR genres. For example, in order to examine the appropriation of genre and genre resources, it is interesting to consider: (i) in what way the Executive Summary of the PR/communication plans satisfies the requirements of sales promotional materials, and (ii) how in a very subtle manner, promotional elements are incorporated in the Situation Analysis Section, resulting in a mixed and embedded genre and discourse, achieving a mixture of communicative purposes in the communicative context: to report and to recommend communicative actions as well as to achieve 'private intentions' within the context of 'socially recognized communicative purposes' (Bhatia 2002).
\end{abstract}

\section{Introduction}

Undoubtedly, in recent years, the world as a whole, as well as the present world of work, has seen rapid changes which have served to bring about fundamental changes to work practices, employment and the patterns involved in recruitment. The need has arisen to develop new proficiencies, arising from such skills as language, literacy, communication and learning to learn. Employees, as well as those training them, are thus facing greater challenges to achieve the required competencies needed in this changing workplace environment.

Up until now, professional discourse has been seen as a simple exercise in discursive construction, however, in recent years Bhatia $(2004,2010,2014)$ has developed the notion of "interdiscur-

\footnotetext{
* Jane Lung

School of Business

Macao Polytechnic Institute

Rua de Luis Gonzaga Gomes,

MACAO, SAR, China

wylung@ipm.edu.mo
} 
sivity" to examine the real nature of professional discourse as being an interdiscursive collaborative phenomenon. In line with Bhatia, Lung (2014), when examining the needs of hoteliers in the workplace, maintains that apart from the simple traditional needs analysis approach when training staff, it is vital that critical genre analysis be employed to arrive at the actual required workplace compentencies of employees, including the information needed and the communication skills required.

Bhatia (2013) observes that while the analyses of legal discourse have focused largely on 'discursive practices', very little effort has been given to studying 'critical performance' in professional legal practices, which is distinct from discursive practices. For this reason, this paper aims to show why discursive output has proved insufficient in this dynamic and complex discourse world of the present day workplace, as well as how the application of Critical Genre Analysis (CGA) greatly assists our understanding of it. For example, by using critical genre theory, this paper looks more closely at interdiscursivity in public relations (PR) involving professional communication and how this in turn results in greater understanding of the real nature of the PR profession.

\section{Genre and Professional Practices}

As regards the study of genre, Bhatia (2004) advocates Critical Genre Analysis when he presents the history of written discourse studies. To quote his words, 'Critical genre theory offers a complementary methodological alternative in the form of a discourse-based investigation of a range of professional, organizational and institutional practices' (Bhatia, 2010: 466). In this respect, he sees the historical development of written discourse as being accomplished in three stages including textualization, organization and contextualization. As regards the latter, he points out, that this term, contextualization, includes not only the immediate text but the context in which the text is found. In this sense, it incorporates both the communicative purpose and the communicative context. Bhatia (2004) also proposes a multi-dimensional and multi-perspectival view of genre analysis, which includes three overlapping spaces of analysis: (1) Textual Space where discourse can be analysed as text and as textual knowledge; (2) Socio-Cognitive Space where discourse can be analysed as genre and genre knowledge, on the one hand, and as professional expertise and professional practice, on the other; (3) Social Space where discourse can be analysed as social practice and social pragmatic knowledge.

In this respect, two opposite poles are presented offering a multi-perspectival view. While the pedagogical perspective on one pole goes from the text towards the social practice, the socio-critical perspective on the other pole goes from the social practice towards the text. Further to this, and drawing on this as a framework, Bhatia (2010) maintains that most forms of professional discourse operate simultaneously within and across four somewhat different but overlapping levels so as to construct meanings in typical professional contexts. These levels are: (1) textual (discourse as realization of textual knowledge), (2) genre-specific (discourse as an instance of genre in specialized English for Specific Purposes contexts); (3) professional practice (discourse as a resource to accomplish professional practice), and (4) professional culture (discourse as professional culture). Thus, a comprehensive and insightful analysis of any professional communication needs to be considered and integrated with all these semiotic resources, that is, textual and intertextual resources, generic conventions, professional practices, and professional cultures.

Moving from text to context and from discursive to professional practice, Bhatia (2010) proceeds a step further by focusing on interdiscursivity as interaction between discursive and professional practices in the context of specific professional, corporate and institutional cultures. Going beyond genre analysis and focusing on textual organization, Bhatia considers external factors (i.e. discursive practices, discursive procedures, disciplinary or professional cultures) establishing relations both within and across genres as he argues that interdiscursivity explains different discursive processes and professional practices, often resulting in the 'mixing', 'embedding', and 'bending' of generic norms in professional contexts (Bhatia 1995, 1997, 2000, 2004). Thus, 'in- 
terdiscursivity' refers to more innovative attempts to create different forms of hybrid and relatively novel constructs. This is often done by appropriating or exploiting established conventions or resources associated with other genres and practices. To illustrate, there could be an appropriation of semiotic resources which may include textual, semantic, socio-pragmatic, generic, and professional ones across any two or more of these different levels, especially those of genre, professional practice and professional culture. These appropriations across texts thus give rise to intertextual relations; however, where appropriations occur across professional genres, practices, and cultures, these constitute interdiscursive relations.

Critical Genre Analysis (CGA) is thus an approach "to the analysis of professional genres, while at the same, extending the scope of the construction, interpretation and use of professional genres by focusing on the academic and professional "practices" that most academics and professional experts are engaged in as part of their daily routine within what Bhatia (2010) calls "sociopragmatic space" in which such professional genres invariably function" (Bhatia 2012: 17).

In light of the foregoing, then, how has CGA proved an asset in the field of academic and professional contexts? In effect, it has done so not only by describing but also 'demystifying' professional practices or actions through the medium of genres. To clarify the matter further, Bhatia (2012) goes on to state that this approach focuses on a number of important factors, for example, on both generic artifacts and professional practices, on what is explicitly said and implicitly said or perhaps not even said in genres, socially recognized communicative purposes, as well as an individual's 'private intentions'.

To illustrate, the following sections take up the case of applying Critical Genre Analysis to examine interdiscursivity in public relations (PR) communication by using Bhatia's multi-perspectival and multi-dimensional genre analysis framework so as to understand the real nature of the PR profession.

\section{Contemporary Public Relations and the World of Business}

The Institute of Public Relations' (IPR) Official Statement defines public relations as "the way organisations, companies and individuals communicate with the public and media" (IPR). Broom and Sha (2013: 25) further define it as "the management function that establishes and maintains mutually beneficial relationships between an organization and the various publics on whom its success or failure depends". In turn, The Chartered Institute of Public (CIPR) goes on to state that:

\footnotetext{
Every organisation, no matter how large or small, ultimately depends on its reputation for survival and success. Customers, suppliers, employees, investors, journalists and regulators can have a powerful impact. ... In today's competitive market, reputation can be a company's biggest asset - the thing that makes you stand out from the crowd and gives you a competitive edge. Effective PR can help manage reputation by communicating and building good relationships with all organisation stakeholders. (- Courtesy of Chartered Institute of Public Relations in Broom 2012: 25)
}

However, in view of the fierce competition that exists in the world of business today, how can organisations distinguish themselves from the competition in order to win new customers and retain the existing ones? Obviously, there is a need to make a company stand out from the crowd as well as make it more appealing and interesting to both members of the public and the media. All of this is achieved by creating and maintaining a positive public image. In this respect, either a PR specialist or a PR firm can provide assistance. For example, first, by helping them create and maintain a good reputation among the media and the customers; then, by communicating on their behalf and presenting their products, services and overall operation in the best light possible. The result of such a positive, public image is a strong relationship with customers which in turn increases sales. Thus, the CIPR Official Statement defines Public Relations as the discipline which looks after reputation, and reputation is "the result of what you do, what you say and what others say about you". Hayes et al. (2013:3) simply define it as "relations with publics" and "interrelationships with publics". 
When defining 'public relations', CIPR highlights the aim of earning understanding and support as well as influencing opinion and behaviour. These efforts are deliberate, planned and sustained in order to establish and maintain goodwill and mutual understanding between an organisation and its publics. Lesly (1998) further maintains that public relations helps an organisation and its publics adapt mutually to each other. These concepts are essential, as Diggs-Brown (2012: 6) defines:

\footnotetext{
Public Relations is an applied discipline within the field of communication that uses strategic thinking, planning, research and practice to help an organization or person establish and manage mutually beneficial relationships and interact with an audience or audiences that ensure success or failure; position an organization, person, or issue favorably within the marketplace of ideas; and/or affect the attitudes, opinions, and behaviours of the targeted audience or audiences.
}

Separately or together, these definitions are useful for reflecting the nature of contemporary public relations, highlighting different aspects of today's public relations, but with the following characteristics in common: PR requires (i) communication, including language and communication skills; (ii) planned and strategic thinking; (iii) audience knowledge and focus; and (iv) a management function within or for an organization. Thus, at its core, public relations is the key to effective communication.

However, sadly, experience has shown that many enterprises, and in many instances senior executives, are very poor at communication. As a result, they have, therefore, often looked to public relations practitioners to perform this vital function, at the same time turning to the PR industry for training in the essential skills of effective communication.

Rex F. Harlow (in Broom \& Sha 2013: 28), after collecting 500 definitions of public relations, identifies common elements and incorporates them in the following definition:

\begin{abstract}
Public relations is the distinctive management function which helps establish and maintain mutual lines of communication, understanding, acceptance and cooperation between an organization and its publics; involves the management of problems or issues; helps management to keep informed on and responsive to public opinion; defines and emphasizes the responsibility of management to serve the public interest; helps management keep abreast of and effectively utilize change, serving as an early warning system to help anticipate trends; and uses research and sound and ethical communication as its principal tools.
\end{abstract}

From the above definition, the discursive and professional practices in public relations seem to be both strategically and analytically complex. The analysis of related texts has also shown that public relations practitioners need to possess discursive competence, consisting of textual competence, generic competence and social competence (Bhatia 2004). Discursive competence in a professional context refers to the ability to identify, construct, interpret and use a specific repertoire of professional genres in order to participate in the activities of a specific professional culture, at the same time exploiting generic resources to create new forms, in this way, as Bhatia further elaborates, claiming ownership of a set of relevant genres in a professional context (Bhatia 2009). Thus, not only do public relations practitioners need to be able to have recourse to a range of linguistic and discoursal strategies, they also need to understand the social components in the communicative contexts of their workplace, all of this in order to seek collaborative efforts and to achieve communicative purposes and maintain good relations with the public. Doing so can establish and maintain goodwill and mutual understanding between an organization and its public.

In view of this, the traditional focus of discursive output (written or spoken) and text-internal resources seems to be insufficient to analyse the dynamic and complex discourse of the real world at the workplace. Bhatia (2004) states that both discursive and professional practices are embedded within specific disciplinary, professional and institutional cultures and contexts. Thus, in order to gain a comprehensive understanding of the motives and intentions of professional practices one must look beyond textual constraints. It is essential to analyse the multiple discourses, actions and voices used in discursive acts as seen within the contexts of specific institutional and organizational practices and cultures. In this way, Bhatia has developed the notion of 'interdiscur- 
sivity' describing the situation of appropriating both contextual and text-external generic resources within and across professional genres and professional practices (Bhatia 2004: 7). He further comments that 'professional' contexts are generally rich in 'interdiscursivity' (Bhatia 2008, 2010, 2012). In fact, writing within a professional culture, especially in PR contexts, is essentially an interdiscursive phenomenon to achieve specific professional goals and objectives. In a down-toearth or 'socio-pragmatic' way, professional identities and more specifically, public relations, are negotiated through a dynamic range of professional genres (Bhatia et al. 2013).

\section{Discursive and Professional Practices in Public Relations}

In light of the preceding discussion, this section now looks into language and communication demands in public relations to identify the typical skills and daily activities required by public relations practitioners. What are some of the discursive and professional practices in public relations contexts, such as the use of professional genres and the professional practices that public relations practitioners are engaged in as part of daily routines within their "socio-pragmatic space" (Bhatia 2010)? The section examines the information collected from (i) in-depth interviews with PR practitioners, and (ii) PR/communication plans - in particular, the Executive Summary and the Situation Analysis sections - as these plans are some of the most important documents in PR contexts and form the basis for strategic public relations. After that, the section will go on to discuss why the focus on discursive output (written or spoken) and text-internal resources is not sufficient and how interdiscursivity in critical genre theory also needs to be applied in order to assist in understanding the dynamic and complex discourse of the real world of the workplace.

\subsection{In-depth Interviews with PR Practitioners}

As an example of a location where the demand for public relations practitioners is becoming more important, especially in the hotel and MICE (Meeting, Incentives, Conferences and Exhibitions) industries, Macao has been chosen. Through in-depth interviews with eight public relations practitioners working in gaming, hospitality, MICE industries as well as government departments, this part of the study seeks to gain public relation practitioners' perceptions on their daily activities and the communication skills they require to improve their effective professional communication. In order to further understand the challenges that face PR professionals, an in-depth interview was also conducted with a senior PR manager who has been working in the field in Hong Kong for almost thirty years.

This part of the study sought to answer the following questions:

1. What are some of the daily activities (including genre use) that public relations practitioners need to perform and how important are these activities?

2. What levels of English language and communication skills are required when performing these activities?

3. Do they feel that their English language and communication skills are adequate to meet the communication demands of their workplace? What are some of their challenges?

The results of the interviews indicate that communication skills are very important to public relations practitioners. All the interviewees reported that they had to possess good communication skills in order to communicate with internal staff and external stakeholders effectively. To establish good relations with these people (whether the media, the employees or the public), having good interpersonal communication skills is considered a must and possessing language skills, especially English language skills is certainly an advantage as English is becoming more and more important in Macao.

These informants reported that the most important daily tasks they had to perform included promoting the good reputation or image of the company; communicating with the public; commu- 
nicating with the media; planning and organizing events (such as press conferences, open house and exhibitions); and writing communication plans and press releases. Other important tasks included communicating with colleagues and clients. In order to accomplish these tasks, they had to manage to (i) plan, develop and implement communication programmes and campaigns; (ii) prepare media kits and writing news for the media, including news releases, fact sheets, backgrounders, and photo captions; (iii) write speeches and talking points for spokespersons of the organization; (iv) plan and coordinate conferences and meetings for media and stakeholders; (v) write and edit publications for internal staff and external stakeholders, such as newsletters and interim/annual reports; (vi) speak on behalf of the company in news conferences if the spokesperson is not available; (vii) attend news interviews, special events, conventions, meetings and other external activities; (viii) devise and coordinate photo opportunities; (ix) collate and analyze media coverage; $(\mathrm{x})$ organize events such as open house and press tours. One of the informants said that she was working in a small firm and there was no Public Relations Department, so she had to handle all the tasks that were related to public relations on her own. Others reported that at times they had to hire a public relations agency/firm and work with them in order to accomplish some of the tasks.

They commented that the rapid socio-economic development of Macao over the last decade had caught the attention of foreign investors to do business there, so their companies and many large companies had to use English as the language of their workplace, even though the official languages in Macao are Chinese and Portuguese. They all felt that an excellent level or good level of the four language skills (listening, speaking, reading, and writing skills) would enable them to perform their daily tasks effectively, as it was important for public relations practitioners to communicate with people from different parts of the world. Dealing with the public, clients, media over the phone and video conferences demanded greater listening and speaking skills than compared to dealing with colleagues. Communication plans, media plans, letters, memos, emails and faxes, research, reports, social networking and the use of computers would require a higher level of reading and writing skills. However, the informants remarked that very often they had to use all four skills in order to accomplish a task, so it would be difficult to prioritize any skill sets over the other.

When asked whether they felt that their English language and communication skills were adequate to meet the communication demands of their workplace, all the informants reported that their companies had provided training courses for them focusing on how to use English to communicate with clients and the media. For example, how to write press releases, how to handle clients and respond to complaints or how to speak politely when liaising with and answering enquiries from the media. Even though the informants felt that these training courses were in some way relevant to their work, they felt that the training courses were of very little help because sometimes their work did not mainly involve language, but very often merely a matter of considering the best way to do the tasks. Thus, the current overall improvement did not seem to measure up to the standard required in the workplace when considering the multi-tasks that public relations practitioners had to perform and the importance of having a high level of English proficiency to perform these multi-tasks effectively and successfully given tight schedules and stressful deadlines.

These informants further commented that they had to make day-to-day decisions on many practical and specific issues, such as whether they should send a news release or hold a press conference; whether it would be more effective to have an exhibition in a mall or in a convention centre; and what promotion strategies (print advertisements or publicity brochures) should be used. More importantly, they had to be involved in the strategic planning of their companies, and to anticipate or identify problems which were likely to face their companies. To position their companies in a positive light for the public, they had to make use of communication programmes and campaigns. Thus, the planning of communication programmes/campaigns (including budgeting), and implementation of programmes/campaigns and problem-solving were part of their job. All of 
these required planned and strategic thinking, effective communication skills as well as collaborative efforts. When asked about the challenges, a senior public relations manager working in Hong Kong for almost thirty years added:

\footnotetext{
"I think the most challenging part of a PR practitioner is to be always prepared for an incident to happen any time ... always stay alert because we don't know what will happen tomorrow, so we need to finish the work as soon as possible in case anything unexpected happens... Of course, another challenge is to be able to respond quickly especially in this digital age. Bad news spreads quickly in a viral world. You have to compete with time to better manage the expectations of the public...The first one is the challenge of myself while the second one is more that of the work..."
}

In this respect, what is the importance of the role public relations practitioners play when communication becomes essential between an organization or individual and their publics? First, they must not only be aware of the needs of an organization but also those of their publics. Whether individuals, in-house employees, or consultancies, public relations practitioners must be fully aware of what is required of them. For example, they need to completely understand the communication process in order to develop strategies ensuring that all forms of communication are clear, honest and unambiguous, this with the view that the target audience is left in no doubt as to the message conveyed. Who constitutes these audiences? In many cases, an enterprise can have a number of audiences or stakeholders. In fact, a stakeholder may constitute any individual or body who believes they have a stake in, or are relevant to a government, enterprise or individual. Such bodies may include the media, shareholders of a company, the employees of an organisation, constituents of a politician, customers of an organisation, or the public in general.

As to the tools and methods that a public relations department can use to enhance a company's image, there are many. These might include traditionally used news releases and announcements that are sent to the media. In turn, newsletters are often sent to customers as well as appearances made at public events, such as trade shows or conventions. Modern technology has also speeded things up by means of the Internet, while PR departments have tools such as blogs and social media networks to convey their message.

At this point, it is important to note that certain skills are helpful for people who work in public relations, including a high level of communication skills, both written and verbal. Multitasking and time management are also skills essential for a PR practitioner as well as some form of media background or training to understand how the media work. At the same time, organizational and planning skills are also essential along with the ability to work well under pressure. Obviously, things will not always proceed smoothly so diplomacy is needed, for example, to answer a barrage of questions from the media and members of the public and would undoubtedly prove an asset if a company comes under verbal attack. By taking control of the situation, the PR department is thus able to respond to criticism and in this way protect the company's reputation effectively.

\subsection{A closer look at the interdiscursive collaborative construction of public relations genres}

To illustrate the real nature of public relations discourse as an interdiscursive collaborative phenomenon to achieve professional goals in public relations, this section looks into "interdiscursivity" (as used by Bhatia 2010) and the process of interdiscursive collaboration in public relations contexts. As PR/communication plans are amongst the most important documents in PR contexts and form the basis of strategic public relations, this section examines PR/communication plans collected from forty corporations in both Macao and Hong Kong. It looks closely at two sections: (1) the Executive Summary and (ii) the Situation Analysis of PR/communication plans to show the interaction between discursive and professional practices in the "socio-pragmatic space" of public relations contexts and how interdiscursivity is built into the PR genres. This will demonstrate how Critical Genre Analysis as a tool needs to be applied in order to describe and "demystify" professional practices or actions in public relations through the medium of genres. 
To proceed, it can be seen that in order for an organization to be successful, strategic planning is necessary. For example, communication programmes/campaigns need to be designed in order for an organization to achieve its aims and meet its goals. How is this achieved? Obviously, good strategies and communication planning are necessary. Such communication planning might include improving the reputation/image of a company company-wide, or dealing with a particular opportunity or problem that the company might be facing at the time. Such activity is essential in order to, amongst other things, quickly repair any problem or gap that may have arisen that could adversely affect the business. Such marketing gaps or 'loopholes' could give rise to serious problems, for example, the loss of customers to competitors, loss of sufficient market share, the limiting of the company's market share to one specific audience, and failure to capture a wider audience. Rather than the foregoing, a good PR/communication plan could expand a company's market share in new ways, for example entering an untested market space with a large potential enabling a rapid maximisation of opportunities.

The construction of PR genres, in particular, PR/communication plans is an interdiscursive collaborative effort, involving different PR specialists at different stages using different resources. Different planners may construct their PR/communication plans in various ways reflecting a variety of views of what public relations are and what they should accomplish. However, a PR/communication plan is usually structured in the following way (i) Executive Summary; (ii) Situation Analysis - SWOT Analysis, Audience Analysis, Problem/Opportunity Statement(s); (iii) Goals and Objectives; (iv) Target Audience; (v) Key Messages; (vi) Communication Strategies and Tactics; (vii) Budget; (ix) Evaluation and Measurement; (x) Appendices.

The following sections will look at the Executive Summary and the Situation Analysis of PR/ communication plans in order to examine how interdiscursivity is built into PR genres, thus showing why the focus on discursive output or typical textualisation patterns is not sufficient, and how Critical Genre Analysis (CGA) also needs to be applied in order to assist in understanding the dynamic and complex discourse of the real world of the workplace.

\subsubsection{Executive Summary}

An Executive Summary of a PR/communication plan appears at the beginning of the plan and is written after the rest of the communication plan is written. It provides a brief synopsis of the key elements such as (i) the problem; (ii) the goal; (iii) target audiences; (iv) audiences objectives (what the audiences are expected to do); (v) major strategies and key tactics that will be used in the campaign; (vi) recommended budget; and (vii) evaluation plans (how to evaluate whether the campaign is successful and the audiences objectives achieved).

This Executive Summary should certainly summarise the rest of the plan. However, by examining it closely it becomes apparent that it is quite different from a summary, in actual fact resembling sales promotion material. In order to examine the appropriation of genres and genre resources, it is interesting to examine such seeming sales promotion material and to consider in what way an executive summary of a communication plan satisfies the requirements of sales promotional material.

To achieve the communicative purposes, a sales promotional letter contains the following moves (Bhatia 1993): (1) Establishing credentials; (2) Introducing the offer - offering the product or service; essential detailing of the offer; indicating value of the offer; (3) Offering incentives; (4) Enclosing documents; (5) Soliciting response; (6) Using pressure tactics; (7) Ending politely. 


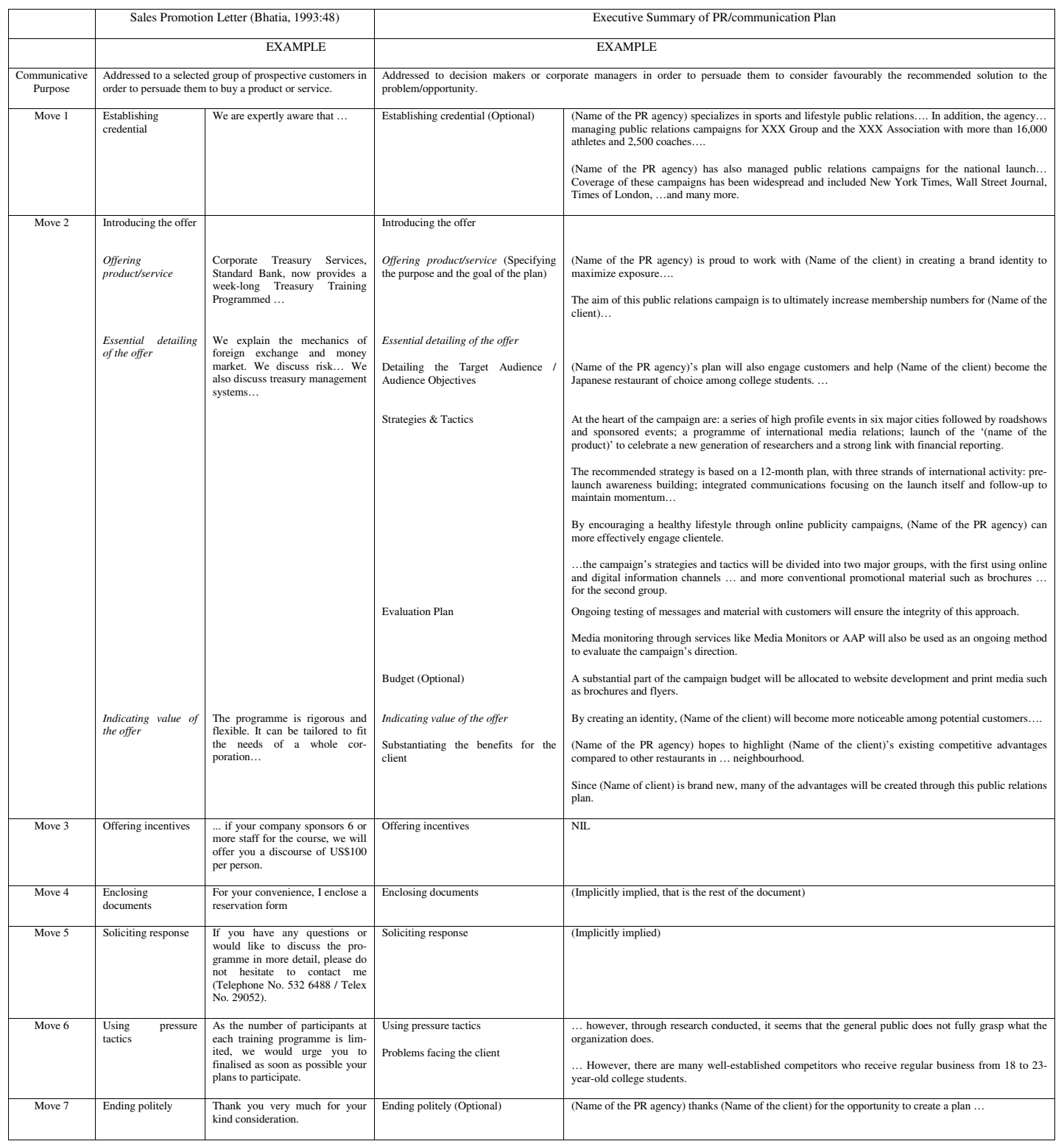

Figure 1. Move structures in sales promotion letters and $\mathrm{PR} /$ communication plans

As revealed by the side-by-side comparison in Figure 1, the key similarity between a sales promotion letter and an executive summary of the PR/communication plan resides in their communicative purposes, and consequently on the move structures used to achieve their purpose. Indeed, while both of them aim at convincing the reader to undertake an action (whether buying a product/service, or approving an action), the communicative purpose of a summary is to make the reader go through the whole document in order to quench the reader's thirst of information. Hence, an executive summary of a PR/communication plan is not a summary, but sales promotion material. A summary is usually informational, giving information about the purpose of the whole document and an overview or preview of its content. Its audience could be specialised or just ordinary readers, so the style sometimes could be technical or static. However, the style of the executive summary of a $\mathrm{PR} /$ communication plan is more managerial, dynamic and enthusiastic. The executive summary is usually persuasive, persuading readers to buy the recommended solution to the problem/opportunity and calling for an action. It does not serve to give an overview of the $\mathrm{PR} /$ communication plan and its purpose is to lay down value propositions (for instance, high profile events; a new generation of researchers; strong link with financial reporting; healthy life- 
style), concentrating on substantiating the benefits for the client (for instance, maximize exposure; increase membership numbers; become more noticeable among potential customers; highlight existing competitive advantages; any of the advantages will be created). It is a solicited or unsolicited sales proposal and its private intention is to sell the proposed plan to the audience who are usually decision makers or corporate managers.

The deliberately promotional effort in the Executive Summary of PR/communication plans illustrates how expert members of professional communities appropriate both contextual and textexternal generic resources to achieve their 'private intentions'. Now, let us look at the Situation Analysis of PR/communication plans.

\subsubsection{Situation Analysis}

The Situation Analysis section is crucial to the process of strategic public relations and forms the foundation of a PR/communication plan. It consists of three major components: (i) SWOT Analysis; (ii) Audience Analysis; and (iii) Opportunity/Problem Statement(s). However, in order to present the current situation facing the company, the practitioner needs to create a research programme to collect the information available and analyse the information needed for the decisions to be made later in the planning process. This calls for a research team and collaborative efforts to conduct the research carefully.

The SWOT (Strengths, Weaknesses, Opportunities and Threats) Analysis is based on widely published materials such as annual reports, statements of company's vision and mission, individual company websites, media coverage as well as survey research and focus group interviews. The Situation Analysis section summarises factors affecting the company (both internal and external contexts), lists key competitors and stakeholders as well as the issues involved. Additionally, the details of internal/external factors, diverse stakeholders (their current views of the company and relationships with the company) and competitors (and their activities) are expanded in appendices and transferred into a database which includes their full contact information for future outreach efforts. Key stakeholders (their wants, needs and expectations about the issue) and competitors are listed in this section, stating how and why these audiences and competitors affect the company. All the information is put into categories and presented in grids or tables to facilitate reading. Such 'environmental scanning' (Grunig et al. 2002) gives marketplace information on what is going on outside the company and amongst the key audiences, identifying environmental actions which may force reactions from the organization, and allows for strategic adjustments. For example an analysis of the strengths, weaknesses, opportunities and threats of the company gives information about the company's place in the market. All the details about the results and research methods are put into an appendix. The major findings will then be incorporated into the communication plan.

Thus, the Situation Analysis section is not only rich in intertextuality, but also in interdiscursivity. With the supportive or illustrative results from the research (e.g. Following extensive research and analysis, the factors and situation affecting...), the Situation Analysis section serves to capture the attention of the reader by highlighting the following points: (i) outline the problem or opportunities (e.g. After numerous customer complaints about the quality of [company name]'s popular [product name], the company faced a tremendous amount of backlash that questioned its stand of quality and reputation); (ii) comment on implications (e.g. As a result, [company name]'s stock has dropped nearly $17 \%$ in the past year, with a loss in revenue of nearly $40 \%$ since last June); and (iii) identify possible consequences if no action is taken (e.g. In order to reestablish [company name]'s profitability and customer satisfaction, the company must work to rebuild its brand reputation and standard of excellence).

The Situation Analysis section of a PR/communication plan helps delineate what actions should be taken and why, including (i) recommendations for communicating; (ii) reevaluating audiences (prioritizing which publics are most important to the company and identifying their demograph- 
ics, psychographics and technographics) and (iii) formulating core messages. This is the key to the success of the strategic process because it also helps highlight the issues, identify the stakeholders and determine the messages. All of these together with the report of the research findings, on the surface, are the communicative purposes of the section. However, the 'private' intention, in fact, is to capture the attention of the reader and to solicit or develop a business opportunity through the support of all the research findings. The Situation Analysis section thus looks more like a marketing document, that is, a marketing discourse incorporating marketing theory (SWOT Analysis) and marketing concepts.

The Situation Analysis section is designed to achieve a mixture of communicative purposes in the communicative context: to report and recommend communication actions as well as to achieve 'private intentions' within the context of 'socially recognized communicative purposes' (Bhatia, 2002). In a very subtle manner, promotional elements are incorporated into the Situation Analysis section, resulting in a mixed and embedded genre and discourse.

Thus, a communication plan calls for the following skills: (i) understand research and planning; (ii) know how to make strategic choices; (iii) make selections from all available tactics; and (iv) complete the process by evaluating programme effectiveness. In view of this and as deduced from the earlier section of this paper, the focus of discursive output or typical textualisation patterns seems to be insufficient to analyse the real world discourse. Thus Critical Genre Analysis (CGA) also needs to be applied in order to assist in understanding the dynamic and complex discourse of the real world of the workplace and to unveil the novel generic forms innovated by expert members of professional communities. For instance, as the senior PR manager working in Hong Kong commented:

\footnotetext{
"The term 'infographic' has become very popular in our field now... It's the trend.... We have to transform all the information into graphics when doing our presentations. ... We usually hire a PR agency to do the communication programmes with us. ... They need to use PPT to present their plans to us and they have to incorporate all the information into graphics. When they submit the plans, they also have to submit the PPT handouts. ... they list out the budget that they need, and we also have to do the budget for our part... they have their teams and we also have our teams ... we work together ... I have to do the coordination ...".
}

Thus, this era has proved to be that of an information era, with novel generic forms used to carry messages to various, ever expanding audiences.

\section{Conclusion}

This paper has shown why a focus on discursive output (written or spoken) is not sufficient and how Critical Genre Analysis (CGA) also needs to be applied in order to assist in understanding the dynamic and complex discourse of the real world of the workplace. By using critical genre theory, this paper looks more closely at interdiscursivity in public relations (PR) involving professional communication, in order to understand the real nature of the PR profession.

Further, the paper attempts to display interdiscursivity of critical genre theory when examining the discursive performance of public relations practices. In other words, it has examined the interdiscursive collaborative phenomenon in a public relations context, that is, the interrelationship between discursive practices (constructing, interpreting, and using PR genres) and professional practices (managing PR activities) by looking into the interdiscursivity built into the PR/ communication plan. It has unveiled the specific motivations or "private intentions" lying behind the choices of interdiscursivity and the underlying force that drives PR specialists to choose interdiscursivity in their profession. Interdiscursivity thus can be viewed as a function of "appropriation of generic resources" to achieve pragmatic effects.

Of interest is the way, noted by both Bhatia (1995) and Fairclough (1995), professional writers are often seen to operate not just within but across generic boundaries thus creating new but related or hybrid forms. In this way, 'private intentions' are still able to be voiced within socially 
accepted communicative practices while using shared generic norms. Thus, 'interdiscursivity' is brought into play across such discursive events as genres, professional activities and inevitably, professional cultures.

Genre analysis examines textual artefacts in terms of pure genres; however, in practice, genres are in mixed or embedded forms in order to achieve a mix of communicative purposes, or individuals' private intentions. Tension between 'genre integrity' and 'genre appropriation' exists as Hyland (2007: 156) states, "Genres are almost never found in isolation in the real world".

Thus, it is not only important, but also essential to use Critical Genre Analysis focusing on interdiscursivity as an interaction between discursive and professional practices in the context of specific professional, corporate and institutional cultures. It is vital to take a multi-dimensional and multi-perspectival view of genre analysis to look at both the immediate text and the context, going beyond a genre analysis focusing on textual organization (i.e. text-internal aspects) to consider text-external factors such as discursive practices, discursive procedures and disciplinary or professional cultures.

As the quality of language and the quality of service in the new economic framework become synonymous (Fairclough 1992), talk is "the lifeblood of all organisations" (Bodenin 1994: 8) and "Language is power, and the power of language is the 'power of genre'. Power of genre is not only to construct, use, interpret and exploit genres, but also to innovate novel generic forms" (Bhatia 2004: 189). It is through and with interdiscursivity that genres and discourse are constructed, interpreted and exploited to achieve their ultimate goals in the real world. Thus, interdiscursivity in Critical Genre Analysis offers a lens to look into the dynamic and complex discourse of the real world of the workplace, assisting in demystifying the complexities of professional practices and actions. It is hoped that continuing work in critical genre theory will strengthen the analysis of professional communication in a wide-range of institutional and professional contexts and help empower practitioners to communicate successfully in the real world of work.

\section{References}

Bhatia, Vijay K. 1993: Analysing Genre: Language Use in Professional Settings. London: Longman.

Bhatia, Vijay K. 1995: Genre-Mixing and in Professional Communication: The Case of 'Private Intentions' v. 'Social Recognised Purposes. In Bruthiaux, Paul/Boswood, Tim/ Du-Babcock, Bertha (eds.), Explorations in English for Professional Communication. Hong Kong: City University of Hong Kong, Hong Kong, 1-19.

Bhatia, Vijay K. 1997: Genre-Mixing in Academic Introductions. In English for Specific Purposes 16, 181-196.

Bhatia, Vijay K. 2000: Genres in Conflict. In Trosborg, Anna (ed.), Analysing Professional Genres. Amsterdam: John Benjamins, 147-162.

Bhatia, Vijay K. 2002: Applied Genre Analysis: A multi-perspective model. In Iberica 4, 3-19.

Bhatia, Vijay K. 2004: World of Written Discourse: A Genre-Based View. London: Continuum.

Bhatia, Vijay K. 2008: Genre Analysis, ESP and Professional Practice. In English for Specific Purposes 27, 161-174.

Bhatia, Vijay K. 2010: Interdiscursivity in Professional Communication. In Discourse and Communciation 21, 32-50.

Bhatia, Vijay K. 2012: Critical Reflections on Genre Analysis. In Iberica, 24, 17-28.

Bhatia, Vijay K. 2014: Analysing Discourse Variation in Professional Contexts. In Bhatia, Vijay K./Bremner, Stephen (eds.), The Routledge Handbook of Language and Professional Communication. London: Routledge, 257-273.

Bhatia, Vijay K./Jones, Rodney H./Bremner, Stephen/Peirson-Smith, Anne 2013: Interdiscursive Collaboration in Public Relations Contexts. In Iberica 25, 127-144.

Bodenin, Deirdre 1994: The Busness of Talk. Organisation in Action. London: Polity Press.

Broom, Glen M. 2012: Cutlip and Center's Effective Public Relations. Pearson Education Ltd.: London.

Broom, Glen M./Sha, Bey-Ling 2013: Cutlip and Center's Effective Public Relations. Pearson Education Ltd.: London.

Diggs-Brown, Barbara 2012: Strategic Public Relations: Audience-Focused Practice. Singapore: Wadsworth Cengage Learning.

Fairclough, Norman 1992: Discourse and Social Change. Cambridge: Polity Press. Fairclough, Norman 1995: Critical Discourse Analysis: The Critical Study of Language. London: Longman. 
Grunig, Larissa A./Grunig, James E./Dozier, David M. 2002: Excellent Public Relations and Effective Organisations. Mahwah, NJ: Erlbaum.

Hayes, Darrell C./Hendrix, Jerry A./Kumar, Pallavi D. 2013: Public Relations Cases. Singapore: Wadsworth Cengage Learning.

Hyland, Ken 2007: Genre Pedagogy: Language, Literacy and L2 Writing Instruction. In Journal of Second Language Writing 16, 148-164.

Lesly, Philip 1998: Handbook of Public Relations and Communications. New York: AMACOM.

Lung, Jane 2014: A Blended Needs Analysis: Critical Genre Analysis and Needs Analysis of Language and Communication for Professional Purposes. In Bhatia, Vijay K./Bremner, Stephen (eds.), The Routledge Handbook of Language and Professional Communication. London: Routledge, 257-273. 